\title{
Methylcytosine Dioxygenase TET3
}

National Cancer Institute

\section{Source}

National Cancer Institute. Methylcytosine Dioxygenase TET3. NCI Thesaurus. Code C162381.

Methylcytosine dioxygenase TET3 (1660 aa, 179 kDa) is encoded by the human TET3 gene. This protein plays a role in oxidative demethylation of DNA. 